\title{
Distribution and determinants of risk of teenage motherhood in three British longitudinal studies: implications for targeted prevention interventions
}

\author{
Dylan Kneale, ${ }^{1,2}$ Adam Fletcher, ${ }^{3}$ Richard Wiggins, ${ }^{2}$ Chris Bonell ${ }^{4}$
}

${ }^{1}$ International Longevity Centre UK, London, UK

${ }^{2}$ Department of Quantitative

Social Science, Institute of

Education, University of London,

London, UK

${ }^{3}$ Department of Social and Environmental Health Research, London School of Hygiene and Tropical Medicine, London, UK ${ }^{4}$ Department of Social Policy and Intervention, University of Oxford, Oxford, UK

\section{Correspondence to}

Professor Chris Bonell,

Department of Social Policy and Intervention, Barnett House, 32 Wellington Square, Oxford OX1 2ER, UK; christopher.bonell@ spi.ox.ac.uk

Accepted 8 May 2012

\section{ABSTRACT}

Purpose In order to consider the potential contribution of universal versus targeted prevention interventions, the authors examined what is the distribution of established risk variables for teenage motherhood? from where in these distributions do births arise? and how does this distribution/determination of risk vary between studies? Methods Secondary data analysis of three British longitudinal studies.

Results For all cohorts and variables, the 'risk' category was the least frequent. Continuous risk factors were normally distributed. A high rate of teenage motherhood within a risk category often translated into low 'contribution' to the overall rate (eg, expectation to leave school at the minimum age among the 1989/1990-born cohort) and vice versa. Most young women had a low probability of teenage motherhood. For any targeting strategy, combining risk factors and a low threshold of predicted probability would be necessary to achieve adequate sensitivity. Assessing between-cohort applicability of findings, the authors find that the numbers of teenage parents is poorly estimated and estimates of the variability and direction of risk may also be inadequate.

Conclusions With reference to a number of established risk factors, there is not a core of easily identifiable multiply disadvantaged girls who go on to constitute the majority of teenage mothers in these studies. While individual risk factors are unlikely to enable targeting, a composite may have some limited potential, albeit with a low threshold for 'risk' and with the caveat that evidence from one population may not inform good targeting in another. It is likely that universal approaches will have more impact.

\section{INTRODUCTION}

Preventing teenage pregnancies and parenthood continues to be a government priority in the UK and other developed nations. ${ }^{1}$ Teenage parenthood is associated with adverse social, economic and health outcomes for mothers and children, ${ }^{2-4}$ which remain for the mothers after adjusting for childhood socioeconomic circumstances. ${ }^{5}$

In countries such as the UK and USA, there is an emphasis on targeted interventions. ${ }^{6} 7$ Targeted approaches, such as early years and youth development programmes, can be effective in reducing risk behaviour and pregnancies among recipients. ${ }^{89}$ However, individual-level effects may not translate into substantial population-level impact. Underlying the focus on targeted interventions is an assumption that there is a core group of multiply disadvantaged individuals who can be identified and who are responsible for a large proportion of outcomes, often informed by notions of 'social exclusion'. ${ }^{10}$ However, these assumptions are not empirically based. Research has largely focused on the size of association between risk factors and teenage pregnancy or parenthood. But even assuming these are causal, they give no indication of risk factors' contribution to overall rates of teenage pregnancy or parenthood nor to the population impact of targeted prevention.

These assumptions may be incorrect. Some interventions use crude or subjective targeting indicators. When targeting employs evidence-based criteria, the populations from which evidence derives may differ from those to be targeted. The very notion of a discrete risk factor may also be misleading. Rose famously suggested that for many outcomes, risk is normally distributed, with most outcomes arising from those at medium risk. ${ }^{11}$ To inform debate about the role of targeted prevention, we draw on data from three British longitudinal studies to assess: (1) what is the distribution of established risk variables for teenage motherhood? (2) from where in these distributions do births to teenage mothers arise? and (3) how does distribution and determination of risk vary between studies? We focus on motherhood rather than pregnancy because women experiencing the former constitute a socioeconomically more distinctive and targetable group ${ }^{12}{ }^{13}$ and because pregnancy data are more subject to retrospective recall error. ${ }^{14}$

\section{METHODS}

The National Child Development Study (NCDS) and the British Birth Cohort (BCS70) involved a census of all births occurring in 1 week in 1958 and 1970, respectively. Both collected data from birth into adulthood. For the NCDS, this occurred at ages $0,7,11,16,23,33,42,46$ and $50^{12}$ and for the $\mathrm{BCS} 70$, at ages $0,5,10,16,26,30,34$ and $38 .{ }^{13}$ NCDS data were originally collected from 8959 women and 9596 men. At follow-up at age 50, responses had declined to $9790 .{ }^{12}$ We use data from age 23 (6234 female fertility histories) to assess teenage motherhood. After accounting for missing data on our predictor variables, a sample of 3957 remains. BCS70 data were originally collected from 17196 cohort members of whom 8279 were women, although participation fell to around 8874 members (4668 women) in the last wave in $2008 .{ }^{14}$ We use data collected at ages 30, 34 and 38 (from a total of 6181 women) to assess teenage motherhood. Of the fertility histories used in the working 
sample of 2752 (after accounting for missing data on covariates), $94 \%$ were derived from age 30 .

The Longitudinal Study of Young People in England (LSYPE) was a school year cohort born between September 1989 and August 1990; ethnic minority and disadvantaged schools were oversampled. Originally, 15770 young people were interviewed and 9636 submitted information on teenage parenthood. For over four-fifths of the LSYPE sample, information was collected between age 19 and 20, so missing some cases. To facilitate comparison with the BCS70 and NCDS, we truncate births of interest up to 19.5 years in these cohorts and only use interviews collected in the 20th year for LSYPE. After accounting for missing data on selected covariates, our analytic sample comprises 3361 (unweighted) young women in LSYPE.

We focused on teenage motherhood in part as discussed earlier because motherhood is less subject to recall error. ${ }^{15}$ All three studies allowed examination of established risk factors for teenage motherhood: low educational expectations ${ }^{16}$ and ability ${ }^{5}$; dislike of school ${ }^{17}$; socially disadvantaged background, including having a father in a manual occupation, ${ }^{5}$ living in social housing and living on benefits ${ }^{18}$; family structure with one or both biological parents absent at age 16 and age of mother and father at birth of study respondent. ${ }^{19}$ While other factors may also explain teenage motherhood, the above factors are chosen for consistency across data sets and represent the main individual-attribute risk factors. ${ }^{20}$ We used the various measures in table 1 but transformed several of our continuous variables into quartiles or used specific cut-off points to aid comparison across data sets. We use early childhood ability as a predictor because of overall consistency among the cohorts as to measurement age.

Attrition and missing data reduced our analytic samples. Our analytic samples represent $40 \%$ of women originally recruited into the NCDS, $31 \%$ of women entering the BCS70 and $44 \%$ of women entering the LSYPE. Those retained in our analysis were more likely than dropouts to lie in the top quartile for educational scores at age $10 / 11$ (28\% vs $23 \%$ for NCDS; $29 \%$ vs $23 \%$ for BCS70; $29 \%$ vs $21 \%$ for LSYPE), to live with both biological parents at age 16 (85\% vs $80 \%$ for NCDS; $84 \%$ vs $73 \%$ for BCS70; $67 \%$ vs $61 \%$ for LSYPE), in households not receiving benefits (97\% vs $95 \%$ for NCDS; $93 \%$ vs $90 \%$ for BCS70) and to report dislike of school (28\% vs $32 \%$ for NCDS; $19 \%$ vs $15 \%$ for $\mathrm{BCS70).} \mathrm{For} \mathrm{the} \mathrm{BCS70,} \mathrm{those} \mathrm{in} \mathrm{our} \mathrm{analysis} \mathrm{were} \mathrm{more} \mathrm{likely}$ than dropouts to live in owner-occupied housing (77\% vs $68 \%$ ). Other differences were not significant. Attrition thus produces less disadvantaged analytic samples for some but not for all measures, although this is less so for LSYPE. Nonetheless, even among the two older studies, the fertility histories for these approximated those from official data. ${ }^{21}$

Rather than limit our analysis to cohort members with complete data, we included a missing indicator dummy for three key variables: father's social class, expectations at age 16 and dislike of school in an analogous manner to other studies using cohort data. ${ }^{22}$ We ruled out multiple imputations because of difficulties developing similar imputation models across studies. After examining risk variable distributions, we then examined what proportion of births to teenage mothers arose from each risk category. We then constructed logistic regression models for the probability of becoming a teenage mother for each cohort and present the output and classification values of these models, descriptively inspecting the difference in the coefficients and presenting the sensitivity and specificity for these models (the proportions of teenage mothers and those remaining childless correctly identified as such at age 19.5 years, respectively). We also calculated the area under the receiver operating characteristics
(ROC) curve for each data set, using packages developed by Newsom ${ }^{23}$ to account for the weighting in the LSYPE. The ROC curve represents the trade-off in detecting cases of teenage motherhood between true-positive and false-positive rates and is a useful measure of the discriminatory power of a model; areas under the ROC curve tending towards 0.5 representing weak discriminatory power, while values of 0.8 and above representing strong power. ${ }^{24}$

We also applied the predicted probabilities from one cohort to another and vice versa, using a method outlined in Thomsen and colleagues $^{25}$ to assess the extent to which the findings from one population could inform targeting in another. Finally, we modelled the predicted logit based on one cohort on the probability of becoming a teenage mother in another. If the value for the logit did not differ significantly from 1.0, then the risk scores from one cohort could be considered a good predictor of teenage motherhood in another. This would allow us to comment on the relevance of using risk factors from one population to inform targeting an intervention for another.

The project was unfunded so no sponsor was involved in our research. We were advised by the London School of Hygiene and Tropical Medicine ethics committee that review was unnecessary because all data were publicly available.

\section{RESULTS}

Table 1 indicates that the prevalence of the categorical risk factors varied from being quite rare (eg, $<8 \%$ for having a teenage mother across all three cohorts) to being very common (eg, over a fifth living in social housing across all three cohorts). However, for all cohorts and categorical variables, the 'risk' category was generally the least frequent. Continuous risk factors approximated to a normal distribution in both cases (not shown; most presented in transformed form in table 1), although early childhood ability was slightly skewed towards more advantaged distribution, particularly within our analytical sample. Our measure of early childhood ability was transformed into quartiles to aid comparability across the data sets. Mother's age at the birth of the cohort member was left untransformed, with a mean and median within a year of each other across all three data sets.

Social housing declined from around two-fifths of the 1958born cohort to a fifth of the 1970- and 1998/1990-born cohorts. There was a rise in those from households in receipt of unemployment benefits from $3 \%$ in the 1958-born sample to $9 \%$ in the $1989 / 1990-$ born cohorts. A rise in lone-parent households was observed, while there were also substantial changes in educational ambitions; over half of the 1958-born sample expected to leave school at the minimum age, this having declined to $18 \%$ in the 1970 -born sample and $8 \%$ in the 1989/1990-born sample. We observe a consistent decline in the proportion of women who had become teenage mothers from around $10 \%$ in the 1958-born cohort to $6 \%$ in the 1989/1990-born cohort.

Table 2 reports the proportion of births to teenage mothers arising from each risk category and the contribution of these to the overall number of teenage births in the sample. In several instances, a high rate of teenage motherhood is observed within a risk category but with little contribution to the overall rate and vice versa. For example, among the LSYPE sample, 19\% of those who expected to leave school at the minimum age had become teenage mothers, this accounting for only $25 \%$ of all teenage mothers; in contrast, only $9 \%$ of those who expected to leave school at age 18 became teenage mothers, this group nonetheless accounted for $35 \%$ of cases of teenage motherhood. In all cases, this reflected the relative scarcity of the risk factor. 


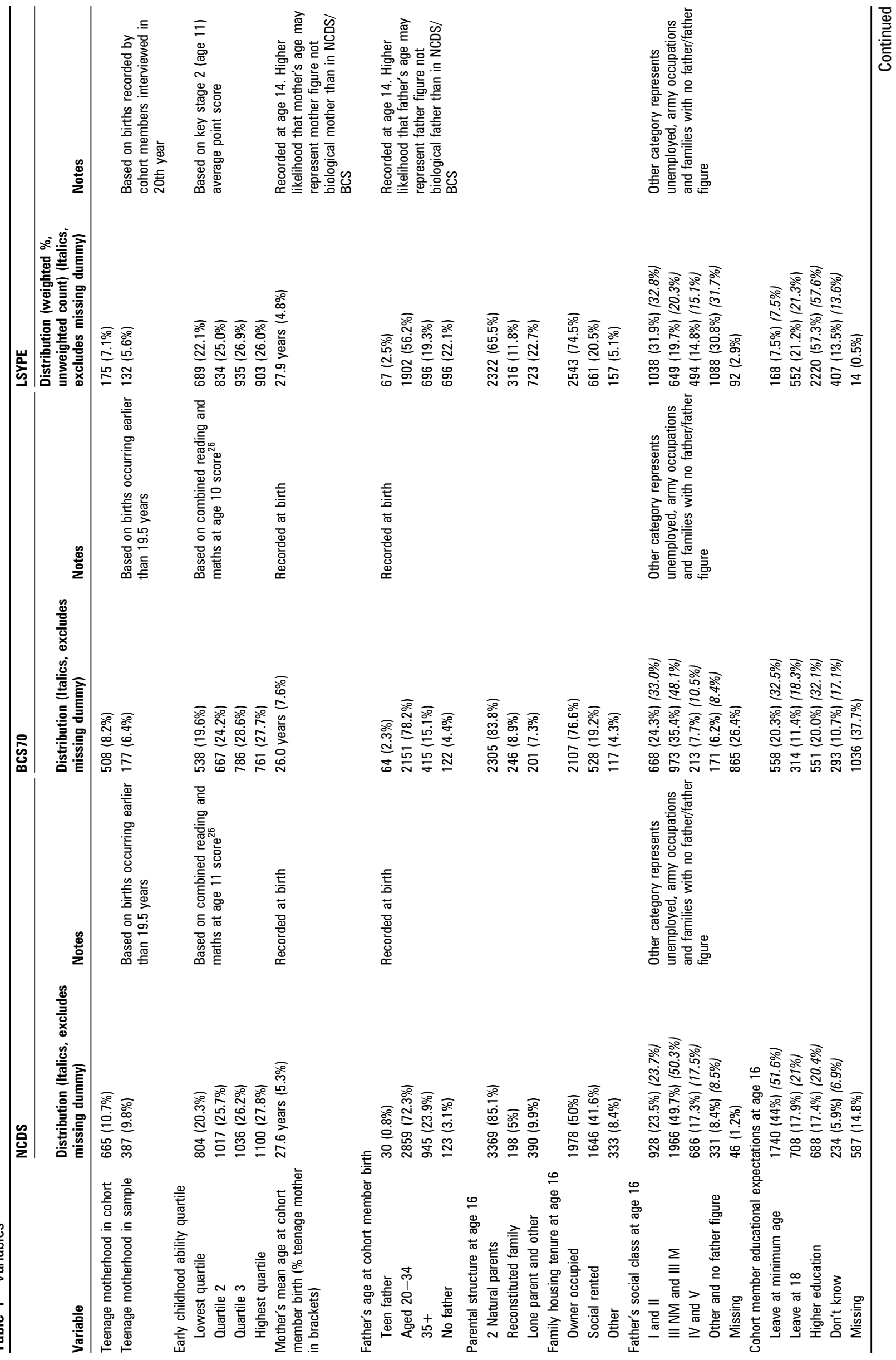




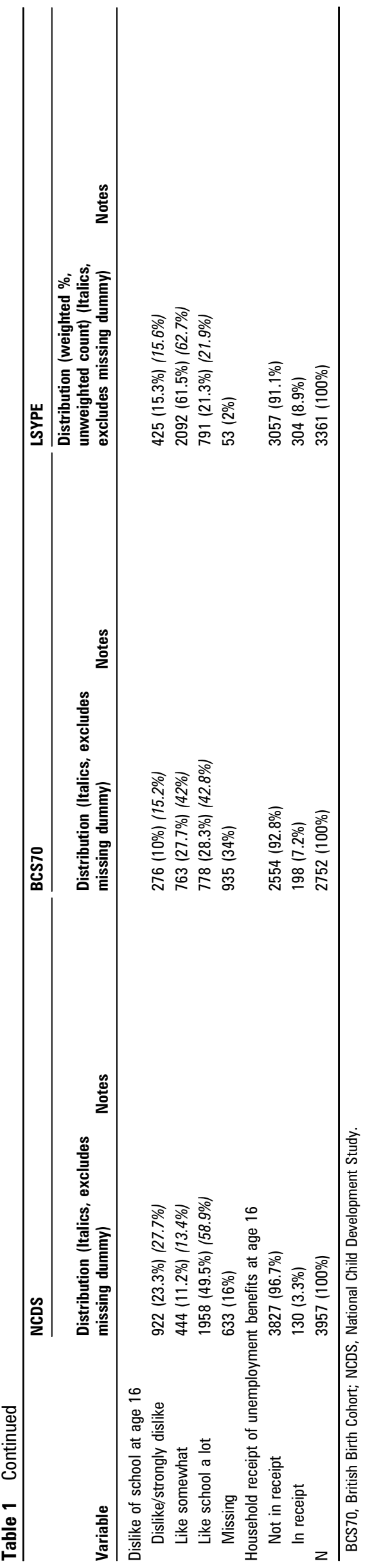

In table 3 , we present the coefficients from three logistic regression models across our samples to examine the relative effect of each variable in predicting teenage motherhood. The relative effect of being in a household in receipt of unemployment benefits or resident in social housing appears to have grown somewhat in terms of predicting teenage motherhood, while father's social class at age 16 appears to be a relatively weak and inconsistent predictor of teenage motherhood across all three studies. Young women's expectation of continuing to higher education was associated with lower risks of teenage motherhood across all three studies and not having clear expectations also had a similar effect across both the younger cohorts. The significance of growing up in a lone-parent household declined in importance over successive cohorts in predicting teenage motherhood, as had dislike of school.

Most young women have a very low predicted probability of becoming a teenage mother. In examining the sensitivity and specificity of our models, we therefore reduced the standard cutoff point of $0.5-0.1$ and $0.05(10 \%$ and $5 \%$ probability) to examine the classificatory power of the logistic models. Table 4 shows that only the LSYPE model has what could be considered adequate classificatory power from the ROC curve, with both the NCDS and the BCS70 models falling short of the critical 0.8 value, suggesting that teenage motherhood was becoming slightly more concentrated among multiply disadvantaged young women within the LSYPE cohort. Our predicted probabilities show that for any targeting strategy, the threshold predicted probability would have to be set at a low value to achieve a sensitivity level of $90 \%$ or above. Achieving high sensitivity in targeting would require significantly reduced specificity, with $90 \%$ sensitivity resulting in around $50 \%$ specificity. This reflects the relative rarity of teenage motherhood as an outcome and the high unexplained variance in models of teenage motherhood.

In examining the applicability of findings from one cohort to another, we might expect given the results in table 3 some departures in actual versus predicted incidence when using the result of one cohort versus another. However, the results suggest that not only would the numbers of teenage parents be underestimated or overestimated using information from one cohort applied to another but that estimates of the variability and direction of risk may also be inadequate in some cases (table 5). When applying the results of the NCDS and BCS70 models onto the LSYPE, although we estimated the direction and variability of risk correctly, we substantially underestimated occurrences of teenage motherhood using the BCS70 and overestimated using the NCDS. When applying results from either the NCDS or LSYP cohorts onto the BCS70, not only did we either substantially underestimate or overestimate occurrences of teenage motherhood, the variability of risk estimated differed significantly as expressed by logit values that differed significantly from 1.0

\section{DISCUSSION}

\section{Summary of key findings}

There is not a core of easily identifiable multiply disadvantaged girls who go on to constitute the majority of teenage mothers in any of these studies. As expected, continuous risk factors approximated to a normal distribution in most cases. Our descriptive results suggest that using any one risk factor for targeting an intervention would be unlikely to reach the majority of those who would become teenage mothers. For example, although girls from households in receipt of 
Table 2 Cases of teenage motherhood by risk factors

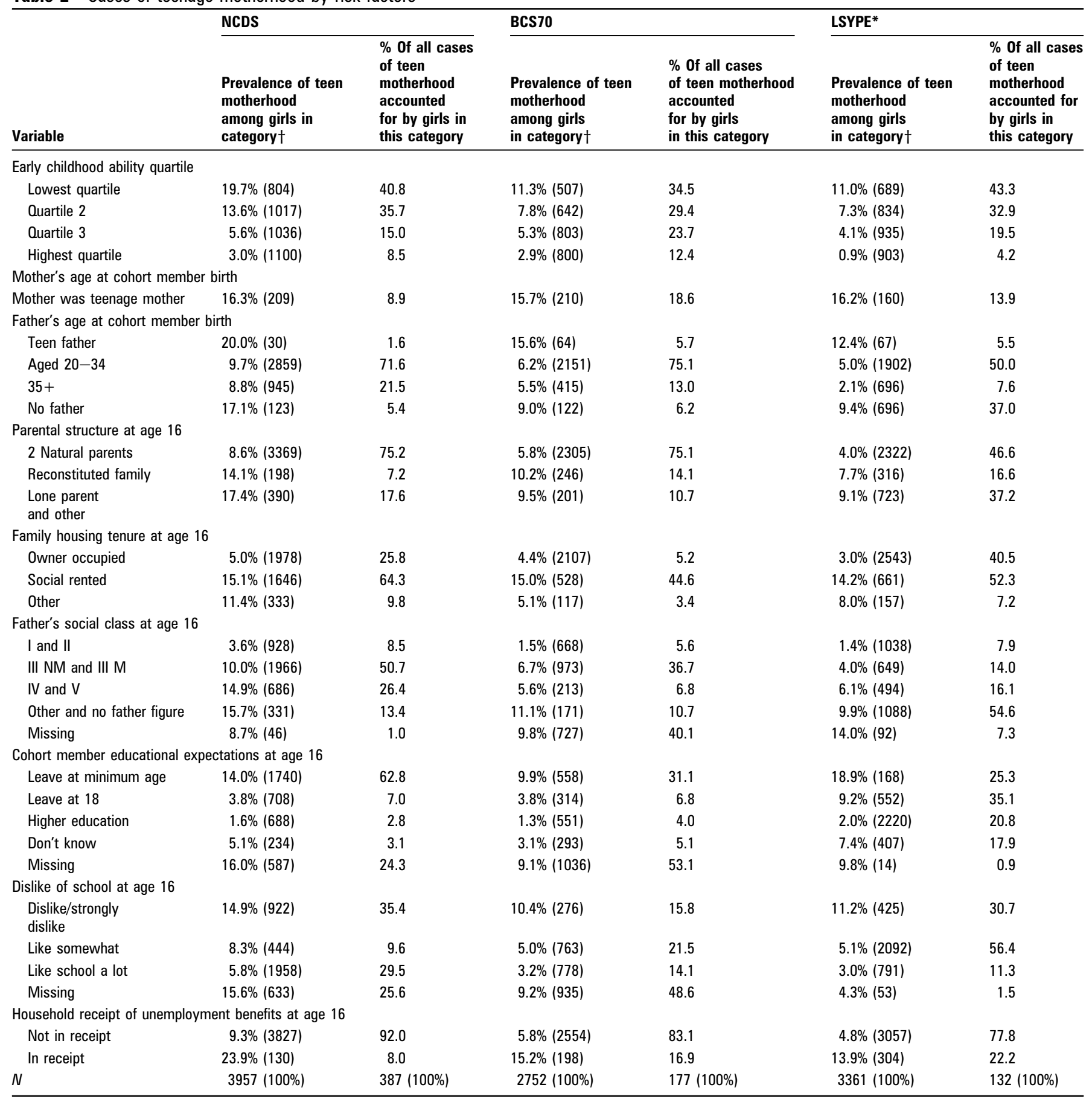

*Unweighted number, weighted proportion.

†Denominator in parenthesis.

BCS70, British Birth Cohort; NCDS, National Child Development Study.

unemployment benefits at age 16 were around twice as likely to become teenage mothers across all three studies, young women in this category accounted for less than a quarter of cases of teenage motherhood. In fact, despite risk of teenage motherhood appearing to have become slightly more socially concentrated among an at-risk group in the most recent cohort, very few young women could be identified as being at high risk of becoming a teenage mother even when all predictors were considered simultaneously.

For any targeting strategy, the threshold predicted probability would have to be set at a low value to achieve sensitivity of $90 \%$ or above. Achieving high sensitivity in targeting would require significantly reduced specificity, with $90 \%$ sensitivity resulting in around $50 \%$ specificity. Furthermore, our examination of the applicability of the results from one sample to another show this varied substantially, some simulations demonstrating that there were substantial variations both in the predicted number of teenage mothers and in the direction and variability of risk. This latter in particular calls into question targeting based on risk factors derived from previous studies.

\section{Limitations}

As outlined earlier, there may be grounds to suspect that attrition may be more problematic in the NCDS and BCS70, given 
Table 3 Model coefficients

\begin{tabular}{|c|c|c|c|}
\hline & NCDS & BCS70 & LSYPE† \\
\hline \multicolumn{4}{|l|}{ Early childhood ability (baseline: lowest ability) } \\
\hline Quartile 2 & 0.805 (0.62 to 1.04$)$ & 0.848 (0.56 to 1.28$)$ & $0.883(0.55$ to 1.41$)$ \\
\hline Quartile 3 & $0.408^{* * *}(0.29$ to 0.57$)$ & $0.651^{*}(0.42$ to 1.00$)$ & 0.697 (0.38 to 1.27$)$ \\
\hline Highest quartile & $0.314^{* * *}(0.21$ to 0.48$)$ & $0.522^{*}(0.31$ to 0.88$)$ & $0.260^{* *}(0.10$ to 0.69$)$ \\
\hline $\begin{array}{l}\text { Mother's age at CM birth (each additional } \\
\text { year) }\end{array}$ & $1.001(0.98$ to 1.03$)$ & $0.957^{*}(0.92$ to 0.99$)$ & $0.945^{*}(0.90$ to 0.99$)$ \\
\hline \multicolumn{4}{|c|}{ Father's age at CM birth (baseline: teenage father) } \\
\hline No father & $0.730(0.25$ to 2.16$)$ & $0.593(0.22$ to 1.62$)$ & 0.717 (0.13 to 3.93$)$ \\
\hline \multicolumn{4}{|c|}{ Parental structure age 16 (baseline: two natural parents) } \\
\hline Reconstituted family & 1.318 (0.85 to 2.05$)$ & 1.326 (0.80 to 2.19$)$ & 1.205 (0.64 to 2.28$)$ \\
\hline Lone parent and other & $2.128^{* *}(1.31$ to 3.45$)$ & 1.123 (0.48 to 2.62 ) & $1.089(0.23$ to 5.06$)$ \\
\hline \multicolumn{4}{|c|}{ Housing tenure age 16 (baseline: owner occupation) } \\
\hline Social classes IV and V & $1.617^{*}(1.03$ to 2.53$)$ & $1.705(0.70$ to 4.14$)$ & $1.861(0.80$ to 4.31$)$ \\
\hline Unclassified or no father & $1.166(0.62$ to 2.19$)$ & $3.527^{*}(1.25$ to 9.99$)$ & $2.392(0.88$ to 6.51$)$ \\
\hline Missing & 1.539 (0.48 to 4.90$)$ & $2.704^{* *}(1.31$ to 5.57$)$ & $5.419 * *(1.74$ to 16.90$)$ \\
\hline \multicolumn{4}{|c|}{ Cohort member educational expectations age 16 (baseline: leave at minimum) } \\
\hline Leave at $17-18$ & $0.470^{* * *}(0.31$ to 0.72$)$ & $0.548(0.28$ to 1.07$)$ & $0.453^{*}(0.24$ to 0.85$)$ \\
\hline Higher education & $0.323^{* * *}(0.17$ to 0.62$)$ & $0.273^{* *}(0.12$ to 0.64$)$ & $0.198^{* * *}(0.10$ to 0.39$)$ \\
\hline Unknown & $0.644(0.35$ to 1.19$)$ & $0.419 *(0.20$ to 0.88$)$ & $0.454^{*}(0.23$ to 0.88$)$ \\
\hline Missing & $1.647(0.74$ to 3.66$)$ & 1.061 (0.54 to 2.09$)$ & $1.298(0.23$ to 7.22$)$ \\
\hline \multicolumn{4}{|c|}{ Dislike of school age 16 (baseline: dislike/dislike strongly) } \\
\hline Like somewhat & $0.686(0.46$ to 1.02$)$ & $0.537^{*}(0.31$ to 0.92$)$ & 0.665 (0.41 to 1.08$)$ \\
\hline Like or like strongly & $0.606 * * *(0.46$ to 0.80$)$ & $0.532^{*}(0.29$ to 0.97$)$ & $0.503(0.24$ to 1.04$)$ \\
\hline Missing & $0.671(0.30$ to 1.48$)$ & $0.555(0.26$ to 1.19$)$ & $0.356(0.07$ to 1.93$)$ \\
\hline
\end{tabular}

Exponentiated coefficients, $\mathrm{Cl}$ in parenthesis.

${ }^{*} \mathrm{p}<0.05,{ }^{* *} \mathrm{p}<0.01,{ }^{* * *} \mathrm{p}<0.001$.

†Unweighted number, weighted estimates.

BCS70, British Birth Cohort; CM, cohort member; NCDS, National Child Development Study.

the longer follow-up time until the collection of fertility histories. Patterns of attrition and missingness suggested that women in our analytical sample were less likely than the population as a whole to be disadvantaged and to be disengaged from school using some indicators, although there was no difference using other indicators. Nevertheless, attrition, wave non-response and item non-response all represent caveats to our findings. The decline in teenage parenthood we observed between successive cohorts over time mirrors national trends, with a decline from $13 \%$ among women born in 1980 to $10 \%$ among women born in 1991. ${ }^{27}$ Similar declines have been witnessed elsewhere recently, with a 2000-2008 decline in the US age-specific fertility rate from 47 births to 40 per 1000 women. ${ }^{28}$ Our estimates for all

Table 4 Area under the ROC curve, sensitivity and specificity using $10 \%$ cut-off

\begin{tabular}{lccc}
\hline Test & NCDS & BCS70 & LSYPE \\
\hline Area under ROC curve & 0.766 & 0.768 & 0.837 \\
Sensitivity (10\%) & $74.4 \%$ & $48.6 \%$ & $52.3 \%$ \\
Specificity (10\%) & $65.3 \%$ & $82.3 \%$ & $89.0 \%$ \\
Sensitivity (5\%) & $89.9 \%$ & $84.8 \%$ & $73.4 \%$ \\
Specificity (5\%) & $44.5 \%$ & $55.5 \%$ & $74.9 \%$ \\
N & 3957 & 2752 & $3361^{*}$ \\
\hline
\end{tabular}

*Unweighted number, weighted estimates.

BCS70, British Birth Cohort; NCDS, National Child Development Study; ROC, receiver operating characteristics. three cohorts are lower than official estimates, and we explored whether this was an artefact of our sample selection and found that sample estimates of teenage motherhood did not differ substantially from cohort estimates, indicating that the lower representation of early births among all three cohorts may be attributable to attrition observable before the collection of fertility information, as opposed to the impact of missingness of our controlling covariates.

Another caveat is there were some differences in the instruments used to measure our indicators (outlined in table 1). Our truncation of births of interest up to 19.5 years in the BCS70 and NCDS ensured comparability with LSYPE but this may mean we underestimated teenage births for some young women interviewed before 19.5 years and overestimated teenage births for others interviewed afterwards. Finally, our analysis focuses on teenage motherhood rather than teenage pregnancy or fatherhood and it is possible that distribution and determination of risk for these outcomes differ from the findings we report for teenage motherhood.

Our analysis draws on individual risk attributes that are most commonly used to target interventions and excludes communitylevel and behavioural risk factors such as, respectively, neighbourhood deprivation and frequency of contraceptive use. A further limitation is that two of the cohorts are now quite old. However, we use this as an opportunity to examine how the determinants of risk of teenage motherhood have changed across time. 
Table 5 Actual and predicted rates of teenage motherhood using information from one cohort applied to another (actual numbers are given in bold, weighted numbers presented for LSYPE); fit of predicted logit and constant

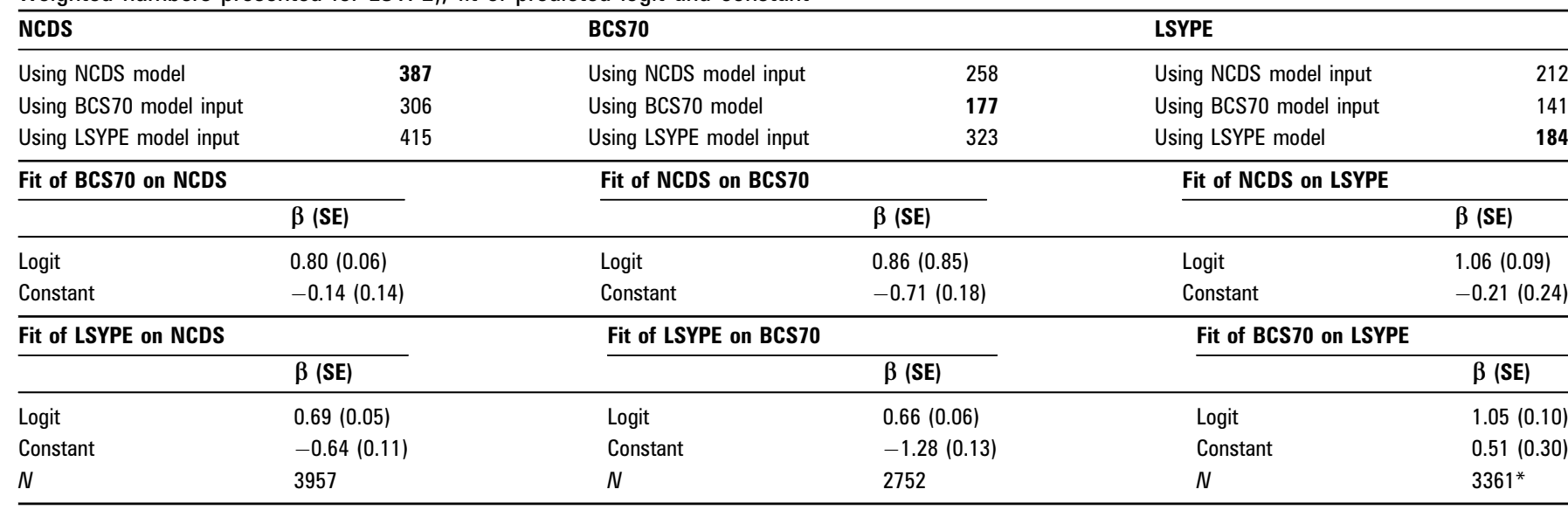

*Unweighted number, weighted estimates.

BCS70, British Birth Cohort; NCDS, National Child Development Study.

\section{Implications for policy and research}

While individual risk factors are unlikely to provide very precise means of targeting interventions, a composite method of assessing risk measuring several factors may have some limited potential, albeit with a low threshold for being 'at risk'. It was only for the LSYPE that the ROC values indicated a model with good classificatory power, which could suggest that the social profile of teenage mothers became less random over time. Should this be so, this could strengthen the argument for targeted interventions. Nevertheless, the generally low predicted probabilities of becoming a teenage mother indicated that targeting those at risk remains problematic even within the most recent study. Furthermore, for a social outcome such as teenage motherhood, the applicability of evidence from one cohort to another is questionable. The determination of risk varies between populations, for example, living in a lone-parent household for the 1958-born cohort was a strong risk factor for

\section{What is already known on this subject}

Teen-pregnancy prevention interventions are commonly targeted but we know little about whether these reach future teenage parents. Epidemiology has concentrated on examining the size of association of risk factors rather than whether those possessing these form a majority of future cases of outcomes.

\section{What this study adds}

Our birth cohort analysis suggests that those possessing specific risk factors constitute a small proportion of future teenage mothers, with risk factors from one cohort being poor predictors of teenage motherhood in other cohorts. Single measures may not facilitate targeting but composites might, as long as thresholds for 'risk' are set low. Universal approaches may be a more promising means of achieving large overall impacts. becoming a teenage mother, but by the 1989/1990 cohort, its predictive significance had waned.

While our findings suggest that targeted interventions to address risk factors such as low aspirations may have some role in broader strategies to address teenage pregnancy and parenthood, in particular in order to address health inequalities, it is likely that universal approaches will have substantially more population impact.

Contributors $\mathrm{CB}$ conceived the paper, planned the analysis and drafted the paper. $\mathrm{He}$ is the guarantor of the paper. DK planned and undertook the analysis and contributed text to the paper. AF and RW contributed to the interpretation of the findings and drafting the paper.

Funding This work was undertaken unfunded

Competing interests None.

Provenance and peer review Not commissioned; externally peer reviewed.

Data sharing statement The data used in this study are already publicly available.

\section{REFERENCES}

1. Holgate HS, Evans R. Sexuality and young motherhood: discourses and definitions. In Holgate HS, Evans R, Yuen FKO, eds. Teenage Pregnancy and Parenthood: Global Perspectives, Issues and Interventions. Abingdon/New York NY: Routledge, 2006:7-23.

2. Ermisch J. Does a 'Teen-Birth' Have Longer-Term Impacts on the Mother? Suggestive Evidence from the British Household Panel Survey. Colchester: Institute for Social and Economic Research, 2003.

3. Boden JM, Fergusson DM, Horwood LJ. Early motherhood and subsequent life outcomes. J Child Psychol Psychiatry 2009;49:151-60.

4. Francesconi M. Adult outcomes for children of teenage mothers. Scand J Econ 2008:110:93-117.

5. Hobcraft J, Kiernan K. Childhood poverty, early motherhood and adult exclusion. Br J Sociol 2001;52:495-517.

6. Social Exclusion Unit. Teenage Pregnancy. London: Social Exclusion Unit, 1999.

7. Brindis CD. A public health success: understanding policy changes related to teen sexual activity and pregnancy. Annu Rev Public Health 2006;27:277-95.

8. Harden A, Brunton G, Fletcher A, et al. Teenage pregnancy and social disadvantage: a systematic review integrating trials and qualitative studies. BMJ 2009;339:b4254.

9. Kirby D. Emerging Answers 2007: Research Findings on Programs to Reduce Teen Pregnancy and Sexually Transmitted Diseases. Washington DC: National Campaign to Prevent Teen and Unplanned Pregnancies, 2007.

10. Levitas R. 'What is social exclusion?' In: Gordon D, Townsend P, eds. Breadline Europe: the Measurement of Poverty. Bristol: Policy Press, 2000.

11. Rose G. The Strategy of Preventive Medicine. Oxford: Oxford University Press, 1992

12. Bhamra S, Gatenby R, Hacker E, et al. Technical Report of the National Child Development Study: 2008-2009 Survey. London: National Centre for Social Research, 2010.

13. Elliott J, Shepherd P. Cohort profile: 1970 British Birth Cohort (BCS70). Int J Epidemiol 2006;35:836-43.

14. Hacker E, Gatenby R, Killpack C, et al. Technical Report of the 1970 British Cohort Study: 2008-2009 Survey. London: National Centre for Social Research, 2010. 
15. Smith L, Adler N, Tschann J. Underreporting sensitive behaviors: the case of young women's willingness to report abortion. Health Psychol 1999;18:37-43.

16. Schoon I, Martin P, Ross A. Career transitions in times of social change. His and her story. J Vocat Behav 2007:70:78-96.

17. Bonell C, Allen $E$, Strange $V$, et al. The effect of dislike of school on risk of teenage pregnancy: testing of hypotheses using longitudinal data from a randomised trial of sex education. J Epidemiol Community Health 2005:59:223-30.

18. Hawkes D, Joshi H, Ward K. Unequal Entry into Motherhood and Unequal Starts in Life: Evidence from the First Survey of the UK Millennium Cohort Working Paper 6. London: Centre for Longitudinal Studies, Institute of Education, University of London, 2004.

19. Meade CS, Kershaw TS, Ickovics JR. The intergenerational cycle of teenage motherhood: an ecological approach. Health Psychol 2008;27:419-29.

20. Kneale D. Pathways to Parenthood: Exploring Context as a Predictor of Time to First Parenthood. London: Centre for Longitudinal Studies, Institute of Education, University of London, 2009

21. Kneale D, Joshi H. Postponement and childlessness: evidence from two British cohorts. Demographic Research 2008:19:1935-68.
22. Hobcraft J, Sigle-Rushton W. Identifying patterns of resilience using classification trees. Soc Pol Soc 2009;8:87-98.

23. Newson R. SENSPEC: Stata Module to Compute Sensitivity and Specificity Results Saved in Generated Variables. http://ideas.repec.org/c/boc/bocode/s439801.html (accessed 15 Jul 2011).

24. Harrell F. Regression Modelling Strategies. New York NY: Springer, 2001

25. Thomsen $\mathbf{T}$, McGee D, Davidsen M, et al. A cross-validation of risk-scores for coronary heart disease mortality based on data from the Glostrup Population Studies and Framingham Heart Study. Int J Epidemiol 2002;31:817-22.

26. Feinstein L, Duckworth K, Sabates R. Education and the Family: Passing Success across the Generations. Abingdon: Taylor \& Francis, 2008.

27. Office for National Statistics. Cohort Fertility. http://www.ons.gov.uk/ons/rel/ fertility-analysis/cohort-fertility-england-and-wales/2010/rft-cohort-fertility-2010.xls (accessed 2 May 2012).

28. Kost K, Henshaw S. US Teenage Pregnancies, Births and Abortions, 2008: National Trends by Age, Race and Ethnicity. New York: Guttmacher Institute, 2012. http:// www.guttmacher.org/pubs/USTPtrends08.pdf 